BMJ Open Sport \& Exercise Medicine

\title{
Assessing the risk for major injuries in equestrian sports
}

\author{
Lara Krüger, ${ }^{1}$ Maike Hohberg, ${ }^{2}$ Wolfgang Lehmann, ${ }^{1}$ Klaus Dresing ${ }^{1}$
}

To cite: Krüger L, Hohberg M, Lehmann W, et al. Assessing the risk for major injuries in equestrian sports. BMJ Open Sport \& Exercise Medicine 2018:4:e000408. doi:10.1136/ bmjsem-2018-000408

Accepted 29 August 2018
Check for updates

\section{(C) Author(s) (or their} employer(s)) 2018. Re-use permitted under CC BY-NC. No commercial re-use. See rights and permissions. Published by BMJ.

${ }^{1}$ Department of Trauma Surgery, Orthopaedics and Plastic Surgery, University Medical Centre Goettingen, Goettingen, Germany

${ }^{2}$ Chair of Statistics, University of Goettingen, Goettingen, Germany

Correspondence to Dr Lara Krüger; lara.krueger@ med.uni-goettingen.de

\section{ABSTRACT}

Background/aim Horse riding is a popular sport, which bears the risk of serious injuries. This study aims to assess whether individual factors influence the risk to sustain major injuries.

Methods Retrospective data were collected from all equine-related accidents at a German Level I Trauma Centre between 2004 and 2014. Logistic regression was used to identify the risk factors for major injures.

Results 770 patients were included ( $87.9 \%$ females). Falling off the horse $(67.7 \%)$ and being kicked by the horse $(16.5 \%)$ were the two main injury mechanisms. Men and individuals of higher age showed higher odds for all tested parameters of serious injury. Patients falling off a horse had higher odds for being treated as inpatients, whereas patients who were kicked had higher odds for a surgical therapy (OR 1.7) and intensive care unit/intermediate care unit (ICU/IMC) treatment (OR 1.2). The head was the body region most often injured (32.6\%) and operated (32.9\%). Patients with head injuries had the highest odds for being hospitalised (OR 6.13). Head or trunk injuries lead to the highest odds for an ICU/IMC treatment (head: OR 4.37; trunk: OR 2.47). Upper and lower limb injuries showed the highest odds for a surgical therapy (upper limb: OR 2.61; lower limb: OR 1.7).

Conclusion Risk prevention programmes should include older individuals and males as target groups. Thus a rethinking of the overall risk assessment is necessary. Not only horseback riding itself, but also handling a horse bears a relevant risk for major injuries. Serious head injures remain frequent, serious and an important issue to be handled in equestrians sports.

\section{INTRODUCTION}

Horseback riding is one of the most popular recreational activities in Europe, ${ }^{1}$ and equine-related accidents increased in the past years. $^{2-4}$ The power of a horse can expose the rider to a potential high-energy trauma. ${ }^{5}$ However, the overall incidence of injuries compared with other sports is described as rather low. ${ }^{6-8}$ In fact the risk of major injuries is of high relevance, hence some authors postulate equestrian sports to be more dangerous than American football, skiing or motor sports. ${ }^{5910}$

The demographics of equine-related accidents were studied a multiple times. ${ }^{41-15}$ In contrast to other high-risk sports, frequently

\section{What are the new findings?}

In equestrian sport, men are at risk for major injuries, with rising age the risk for major injuries rises.

- Despite all prevention measures, head injuries remain the most frequent and serious.

How might it impact on clinical practice?

A rethinking is necessary: risk prevention programmes should include older individuals and males as target groups.

- Helmet use is urgently recommended; a mandatory helmet use should be considered.

young females pursue this sport and comprise a major share in equestrian accidents. ${ }^{41-15}$ Males tend to practice equestrian sports at a higher age. Injured male patients were described significantly older than females. ${ }^{111315}$

Studies evaluating risk factors for serious injuries are scarce, and there is no current consensus regarding individual risk profiles. Individual factors like gender, age and accident mechanism might influence the injury pattern and therapy course.

In order to contribute to the understanding of this popular high-risk sport, this study aims to (1) analyse demographics, accident mechanisms, injury patterns, therapy and severity of equine-related accidents, and (2) assess whether individual factors such as age, gender and injury mechanisms influence the risk to suffer a severe injury. If possible groups of risk for major injuries should be defined.

\section{METHODS}

\section{Data collection}

This is a retrospective cohort study. Digital case histories of all patients registered in the emergency department of the department of Trauma Surgery, Orthopaedics and Plastic Surgery at the University Medical Centre Goettingen between 1 January 2004 and 1 April 2014 were computer-based scanned for keywords ('horse', 'pony', 'riding'). 
Individuals of all age groups involved in an accident while riding or handling a horse, with all kinds of injury, ranging from 'no injury' to 'fatal' were included. Logically not matching patients (eg, 'bike riding'), as well as double entries were excluded.

\section{Patient database}

For 770 individuals, data were collected on accident date and patient demographics (gender and age). Accident mechanisms were categorised in the groups 'fall from horse', 'kicked by horse' and 'other'. We focused on 648 individuals that fell off the horse or that were kicked by the horse since own and previous results identified these two as the main injury mechanisms. ${ }^{11} 1516$ The group of other mechanisms was too inhomogeneous to produce reliable results for them. To classify the body region, injuries were summed up into the following International Classification of Diseases, tenth revision system-based categories: 'head, face and throat', 'trunk', 'spine', 'upper limb' and 'lower limb'.

\section{Injury severity}

As applied before ${ }^{41517}$ clinical parameters were used to evaluate the injury severity. These were an inpatient treatment, surgical therapy, being admitted to the intensive care unit/intermediate care unit (ICU/IMC) and the length of hospital stay in days (LOS).

\section{Statistical analysis}

After presenting descriptive statistics, several regression models were performed to study the effect of gender, age, accident mechanism and injury pattern on the injury severity.

All therapy course variables, except of LOS, were binary. For these binary variables, logistic regression was applied while for LOS a model employing the Poisson distribution was fit. As age affects the therapy variables in a non-linear way $p$ (enalized) splines $^{18}$ were used to model the effect of age. Thus, generalised additive models were fitted. Note that in contrast to previous studies ${ }^{12} 15$ age was not split into categories as there were different proportions of male and female in these categories leading to a bias in the male variable. Additionally, given the small amount of males in the dataset, building categories yielded to having very little observations in each level, that is, being male and being in a certain age group.

All models were estimated using the $\mathrm{R}$ statistical programming language. ${ }^{19}$

\section{RESULTS \\ Characteristics of study collective}

Between 2004 and 2014, 770 individuals were presented to the University Medical Centre with injuries resulting from equestrian sports. In total, $648(84.2 \%)$ of those patients fell off the horse or were kicked by the horse. Table 1 presents the demographics of both patient collectives and the literature reference as shown in table 2.

The larger part of all patients was female $(87.9 \%)$, they were on average about 10 years younger than males. Injuries to the head, face or throat were the leading accident consequence, but also injuries to all other body regions

Table 1 Patient characteristics of all 770 individuals and the subgroup of 648 individuals that fell off the horse or were kicked by the horse

\begin{tabular}{|c|c|c|c|}
\hline & \multirow{2}{*}{$\begin{array}{l}\text { All patients } \\
\mathrm{n}(\%) \\
\end{array}$} & \multirow{2}{*}{$\begin{array}{l}\text { Only fall from horse and kicked by horse } \\
\mathrm{n}(\%)\end{array}$} & \multirow{2}{*}{ Reference, see table $2(\%)$} \\
\hline & & & \\
\hline \multicolumn{4}{|l|}{ Type of accident } \\
\hline Fall from horse & $521(67.7 \%)$ & & $54-81$ \\
\hline Kick by horse & $127(16.5 \%)$ & & $2-24$ \\
\hline Other & $127(16.5 \%)$ & & \\
\hline \multicolumn{4}{|l|}{ Patient characteristics } \\
\hline Female & $677(87.9 \%)$ & $569(87.8 \%)$ & 49-93 \\
\hline Male & $93(12.1 \%)$ & $79(12.2 \%)$ & $7-51$ \\
\hline Mean age in years (SD) & $25.7(14.2)$ & $25.4(12.2)$ & $26-38$ \\
\hline Mean age of females (SD) & $24.3(12.7)$ & $23.9(12.5)$ & \\
\hline Mean age of males (SD) & $36.0(19.9)$ & $35.7(20.4)$ & \\
\hline \multicolumn{4}{|l|}{ Injury pattern } \\
\hline Head, face and throat & $251(32.6 \%)$ & $230(35.5 \%)$ & $17-26$ \\
\hline Trunk & $188(24.4 \%)$ & $173(26.7 \%)$ & $16-32$ \\
\hline Spine & $141(18.3 \%)$ & $127(19.6 \%)$ & $10-22$ \\
\hline Upper limb & $170(22.1 \%)$ & $151(23.3 \%)$ & 8-35 \\
\hline Lower limb & $175(22.7 \%)$ & $114(17.6 \%)$ & $10-31$ \\
\hline Observations & 770 & 648 & \\
\hline
\end{tabular}

Reference to literature as shown in table 2. 


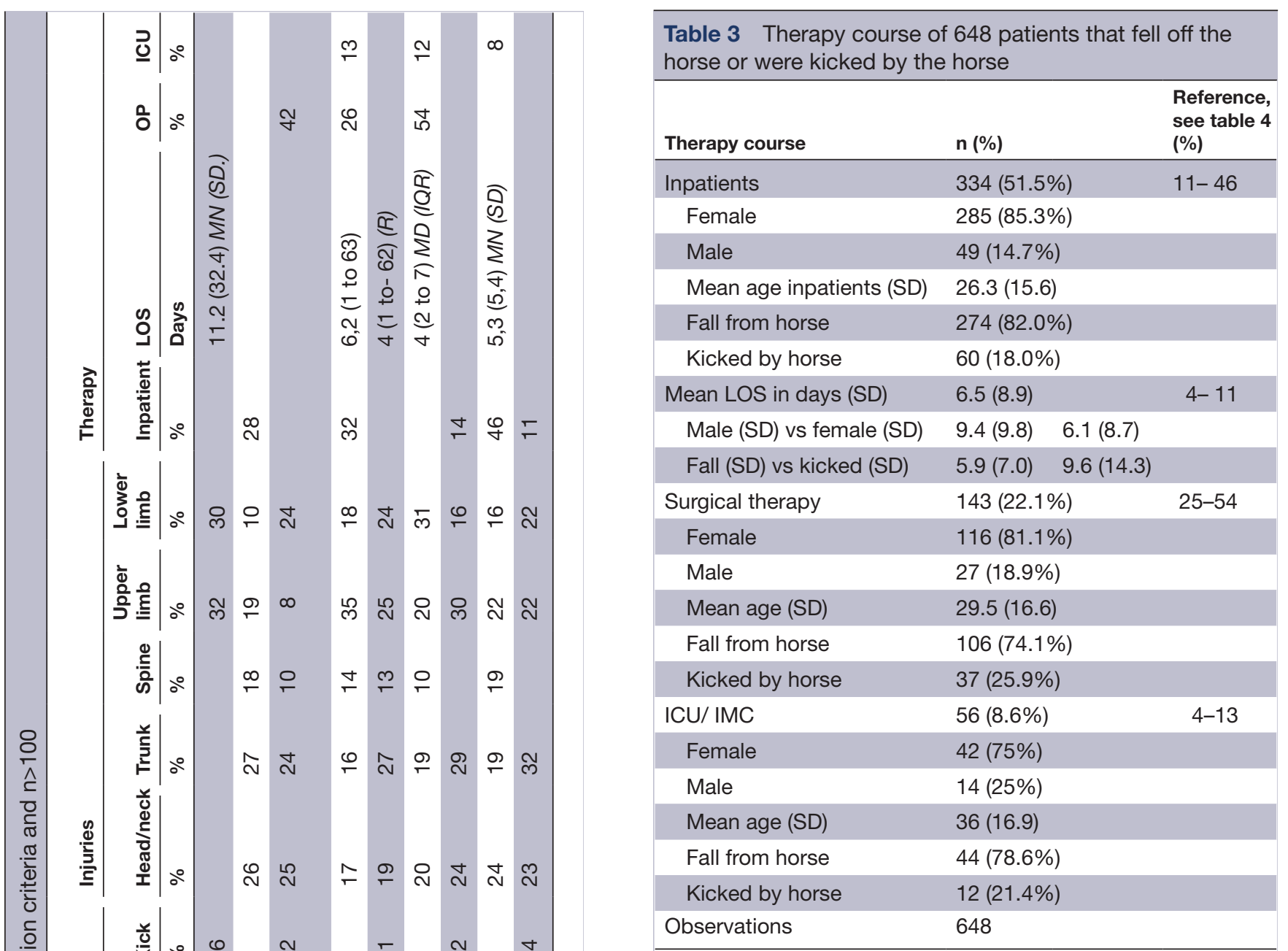

Reference to literature as shown in table 4.

ICU, intensive care unit; IMC, intermediate care unit; LOS, length of stay.

were commonly observed and made up a share of almost one-fifth $(18.3 \%)$ to one-fourth $(24.4 \%)$ of injured patients.

The spinal injuries were prevalently distorsions, commonly at the cervical spine and fractures, mainly at the thoracolumbar junction. There was only one patient with a spinal chord injury and two patients with lesions of the brachial or lumbosacral plexus.

\section{Therapy course}

Table 3 shows the descriptive statistics for the therapy course of the 648 individuals that fell off the horse or were kicked by the horse since the risk analyses were based on this subgroup.

More than half of the patients $(51.5 \%)$ were treated as inpatients after being presented to the emergency room. The mean LOS was 6.5 days with $22.1 \%$ of all patients undergoing surgery and $8.6 \%$ being treated on an ICU or IMC unit.

Males were over-represented in each therapy category. While there were $12.2 \%$ males overall, they made up a share of $14.7 \%, 18.9 \%$ and $25 \%$ of inpatients, patients that underwent surgery and received ICU or IMC 
Table 4 Details of the 196 surgical procedures that were performed for 143 patients, subdivided in primary and follow-up surgery

\begin{tabular}{|c|c|}
\hline Primary surgery & $\mathrm{n}=143$ \\
\hline ORIF or CRIF, all except head & 69 \\
\hline (Limbs) & $(57)$ \\
\hline (Spine) & (9) \\
\hline (Pelvis) & (3) \\
\hline Operative reposition without osteosynthesis & 9 \\
\hline Head-specific procedures & 28 \\
\hline ORIF or CRIF & 20 \\
\hline (Midface with orbital reconstruction) & (8) \\
\hline (Jaw) & (7) \\
\hline (Sole orbital reconstruction) & (3) \\
\hline (Sole midface) & (2) \\
\hline Craniotomy with CSF drainage & 3 \\
\hline Cranial trepanation with CSF drainage & 3 \\
\hline Bulbar reconstruction & 1 \\
\hline Tympanoplasty & 1 \\
\hline Soft tissue procedures & 29 \\
\hline Sutures for reconstruction or bleeding control & 18 \\
\hline Debridement, haematoma drainage, bursectomy & 9 \\
\hline Fasciotomy due to compartment syndrome & 2 \\
\hline Other & 8 \\
\hline $\begin{array}{l}\text { Abdominal procedures (reconstruction aorta, } \\
\text { bleeding control liver, exploratory laparotomy with } \\
\text { splenectomy) }\end{array}$ & 3 \\
\hline Thoracic drainage & 2 \\
\hline Not defined & 3 \\
\hline Follow-up surgery & 53 \\
\hline Removal of implants & 38 \\
\hline Other & 15 \\
\hline Procedures & 196 \\
\hline
\end{tabular}

CRIF, closed reduction internal fixation; CSF, cerebrospinal fluid; ORIF, open reduction internal fixation.

treatment, respectively. Men also spent on average more days in the hospital than females (9.4 vs 6.1).

The mean age, which was 25.4 years for all patients, was higher in each therapy category.

Patients that were kicked by the horse made up a bigger share in all therapy categories $(16.5 \%$ in all patients vs $18 \%, 25.9 \%$ and $21.4 \%$ in the therapy groups) and had a longer mean LOS than patients that fell off the horse (9.6 days vs 5.9 days).

\section{Surgical therapy}

For 143 patients with surgical therapy, 196 procedures were performed (see table 4 ).

The body regions on which the primary procedures were performed are listed in table 5 .
Table 5 Primary surgical procedures divided into body regions

n (\%)

\begin{tabular}{|c|c|}
\hline \\
\hline \multicolumn{2}{|c|}{ Head 47 (32.9) } \\
\hline \\
\hline \multicolumn{2}{|c|}{$\begin{array}{ll}\text { Trunk } & 13(9.1) \\
\text { Upper limb } & 46(32.2)\end{array}$} \\
\hline \multirow{2}{*}{$\begin{array}{l}\text { Lower limb } \\
\text { Spine }\end{array}$} & $28(19.6)$ \\
\hline & $9(6.3)$ \\
\hline Procedures & $143(100)$ \\
\hline
\end{tabular}

For a detailed illustration of the body regions with surgery, see figure 2 .

\section{Evaluation of risk factors by using regression analysis}

Judging from the descriptive, it might be that males, older people and individuals getting kicked by the horse got more severely injured than females, younger people and individuals that fall off the horse. To disentangle these effects, regression analyses were performed (see table 6). The effect of gender, age, accidents mechanism and injured body region on the therapy course was measured. Analyses for the LOS were performed for inpatients $(\mathrm{n}=334)$.

\section{Influence of gender}

Males had 1.4 times higher odds of being hospitalised than females and stayed on average $\exp (0.2)=1.2$ times longer in the hospital after being admitted. The odds for undergoing surgery and for being admitted to the ICU or IMC were also higher for males than for females. However, only the effect for LOS was statistically significant and the group of males admitted to ICU or IMC was with 14 observations (see table 3) quite small.

\section{Influence of age}

The age-depending effect for all therapy variables is illustrated in figure 1 .

The U-shaped graphs in (A) and (C) with a turning point close to 20 years show that up to this age the odds of an inpatient treatment and surgery decreased while it increased after that. Wide CIs for very young and old individuals indicate less observations in these areas. For LOS (B), age increases steadily between the age of 5 and 55 years. Out of this bounds, the estimates vary and become more uncertain. The risk of being treated at the ICU or IMC ward (D) increased with age in a linear way. All age effects were statistically significant on a $1 \%$ level.

\section{Influence of the accident mechanism}

Regarding the accident mechanism the results of risk analyses were ambiguous. Patients that were kicked by the horse had lower odds for being hospitalised than patients that fell off the horse. At the same time they had a 1.7 times higher odds for undergoing surgery, stayed $\exp (0.52)=1.7$ times longer in the hospital when hospitalised. They also had higher odds for being treated in 


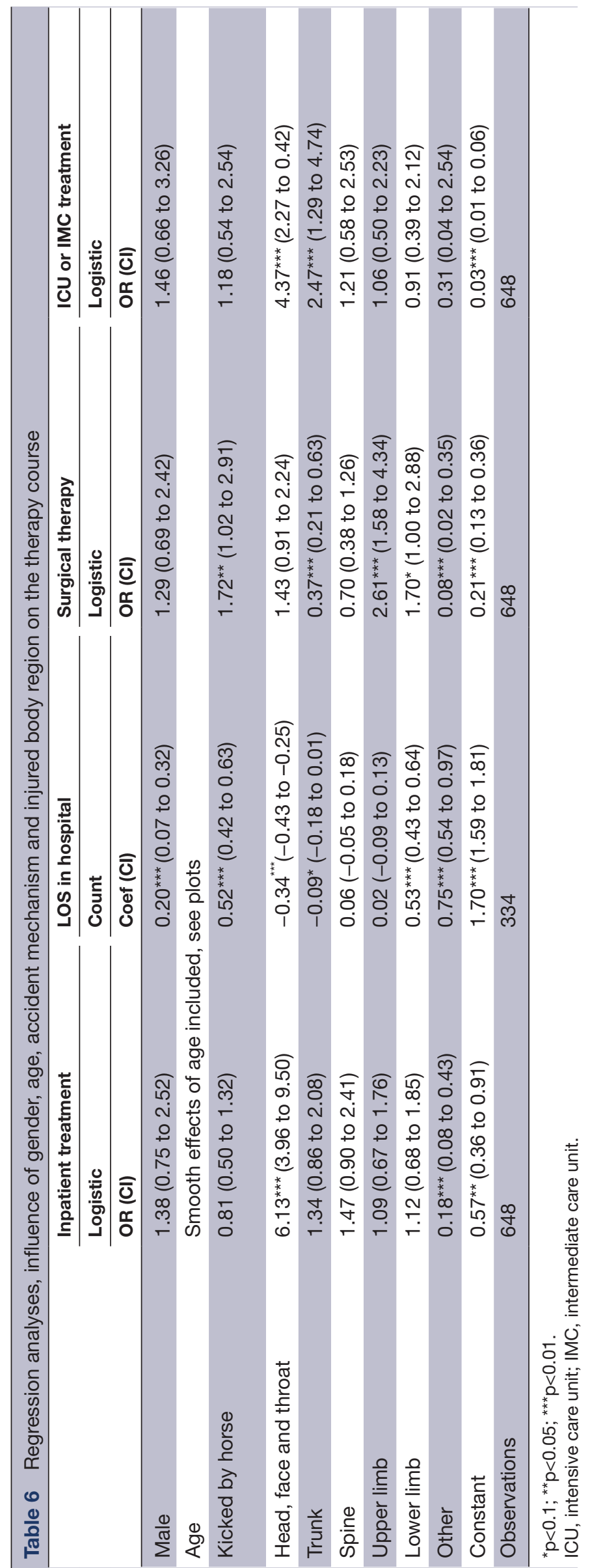


A

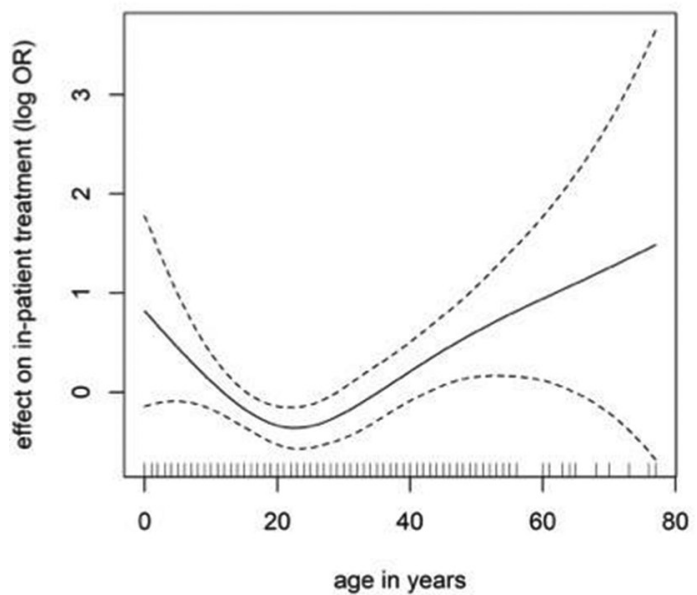

C

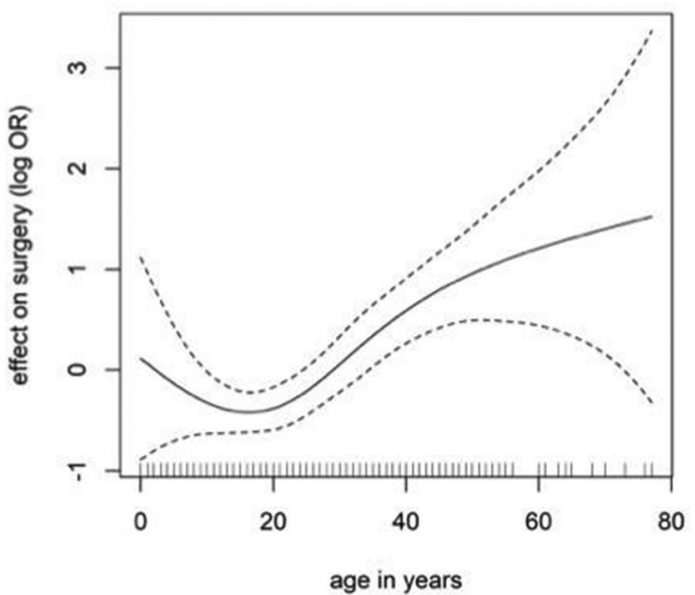

B

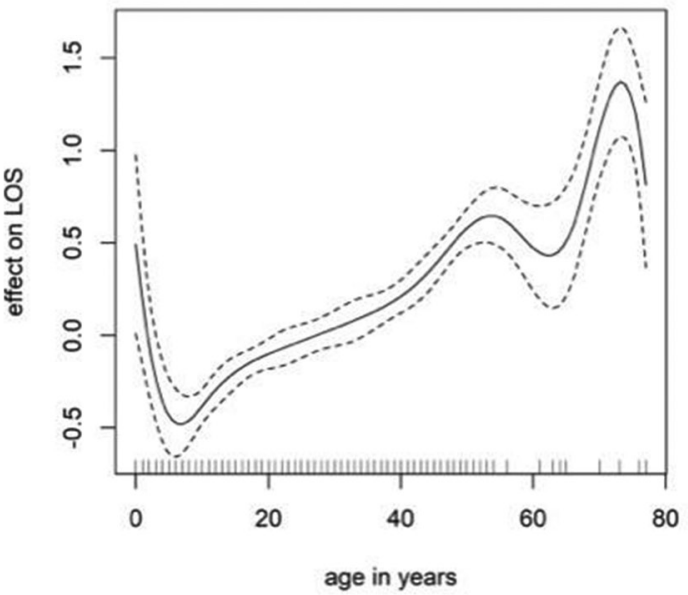

D

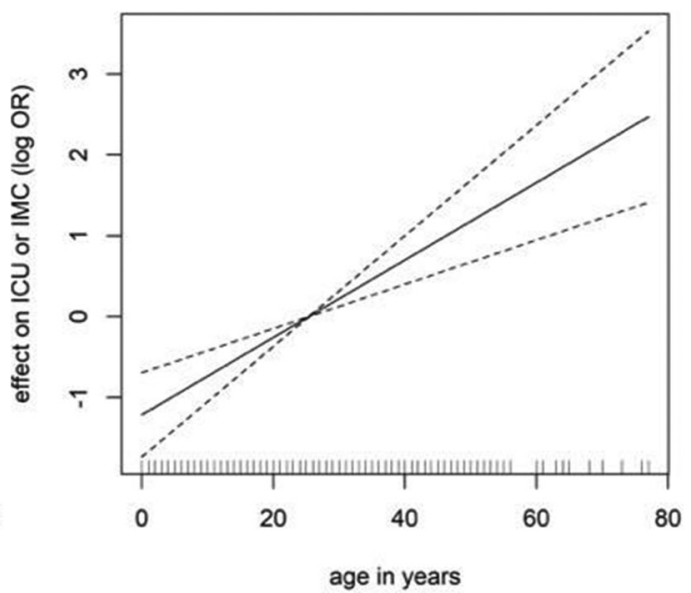

Figure 1 Effect of age on (A) inpatient treatment, (B) length of stay in days (LOS), (c) surgery, (d) intensive care unit (ICU) or intermediate care unit (IMC) treatment. Dashed lines indicate confidence intervals.

intensive or intermediate care though this coefficient was not statistical significant.

\section{Influence of the injured body region}

Focusing on the body region, head injuries increase the odds of being hospitalised the most compared with other body regions. Injuries to the head and to the trunk lead to significant higher odds for a treatment on the ICU or IMC compared with individuals with other injuries. The highest odds for an operation are statistically significantly linked to injuries to the upper and lower limb.

\section{DISCUSSION}

Prevention measures are efficient, when they are addressed to defined target groups. ${ }^{20}$ The purpose of this study was to define groups of risk for serious injuries in equestrian sports. Like this we aimed to contribute to the understanding of a popular high-risk sport. To our knowledge, this study provides the biggest single-centre dataset in Europe. The effect of individual influence factors on the injury severity was disentangled by using regression analyses. Like in other studies with a large dataset ${ }^{491517}$ the injury severity was evaluated using pragmatic criteria of the therapy course (inpatient stay, LOS, operations, ICU/IMC treatment).

Since the University Medical Centre is the only Level I Trauma Centre within a $70 \mathrm{~km}$ range, we assume that the majority of severe accidents in our area was included in the patients collective.

With 770 patients in a 10-year period, equine-related injuries are an important issue to be managed in the emergency department. As illustrated, the characteristics of the described patient collective correspond in all points with the current literature. ${ }^{41-13}$

\section{Male gender as a risk for serious injuries}

Females made up a large share of the patients. However, males were identified as a group of risk prone to serious injuries. They had higher odds for serious outcomes in all tested parameters. We thus confirm recent observations of authors ${ }^{1214}$ who observed same tendencies in their datasets. This shows a contrast to other studies, which did not emphasise any effect of gender. ${ }^{11} 17$ Weber ${ }^{21}$ described women to be in general more riskaverse than men. However, reasons are speculative. 

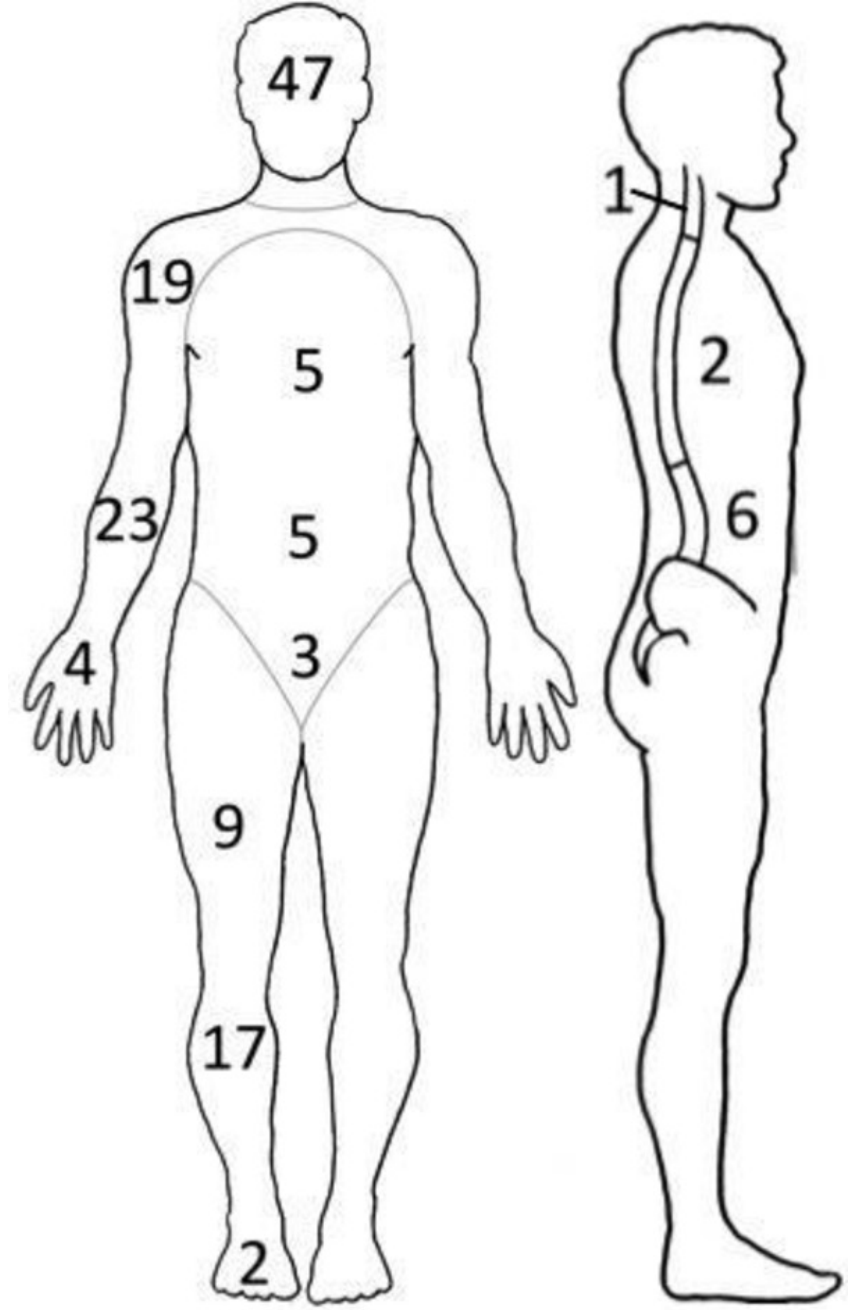

Figure 2 Detailed illustration of the body regions on which the primary surgical procedures were performed.

Note the limitation that in the group of men not all effects reached statistical significance.

\section{Young children should be assessed with care, individuals of higher age are at risk for serious injury}

Patients were not attributed into age groups, thus we were able to analyse the age-depending risk course in detail. The very young patients showed higher odds for being hospitalised and undergoing surgery, but these findings need to be interpreted with caution. The CIs were wide due to few observations. The literature concerning age-related risk for serious injury is scarce. Only one study $^{3}$ observed a higher ISS (7.0 versus 5.5, $\mathrm{p}=0.0002$ ) and hospitalisation rate for patients of younger age. Yet other authors report a notable high incidence of head injuries, in particular concussions, for children. ${ }^{6} 12$ These are followed by the need for hospitalisation and patient monitoring. It remains unclear whether young children are preventively treated with more caution or whether they suffer more serious injuries. However, we share the conclusion of Laurent $e t a l^{3}$ that the very young horseback riders need to be supervised with special care.
With increasing age patients had higher odds for all parameters of serious outcomes. We thus defined them as a group of higher risk and support the findings of previous studies. $^{122022}$ Schicho et $a l^{20}$ suspected a multifactorial genesis: with increasing age the reaction speed, flexibility of ligaments and bone density are decreasing, resulting in more severe injuries at comparable trauma. Bilaniuk et $a l^{12}$ suspected a less careful behaviour. However, we recommend to include individuals of a higher age in future research campaigns.

\section{Horse riding itself as well as handling a horse hase the} potential for serious injury, also bystanders should be alert

While comparing the accident mechanisms, no clear rating of risk was possible. This is in line with the literature: Carmichael ${ }^{16}$ compared mounted to unmounted equestrians and found both to be in the same danger of serious injury. Lang ${ }^{23}$ identified a higher ISS for the group of riders, but a significantly higher rate of surgeries in the group of non-riders. Schröter ${ }^{22}$ postulated that $34.5 \%$ of horse-kick related injuries are potentially life threatening. It is important to state that not only horse riding, but also handling the horse bears a comparable risk for serious injuries. Also bystanders watching sports with no attention in working with horses can suffer major to lethal injuries, for example, by being kicked.

As proposed before ${ }^{16}$ wearing a helmet should be a standard during all activities with the horse. Bystanders should be risk alert and should be advised to keep an adequate distance to the horse.

\section{Head injuries remain frequent, serious and an ongoing issue to handle}

It was illustrated before that the injury pattern resulting from equestrian sports is various. Injuries of all parts of the body play an important role.

In this study, patients with injuries to the head comprised the biggest share. At the same time they were associated with the highest risk for hospitalisation and an intensive or intermediate care treatment. It is remarkable that the head was the body region with the most frequent surgical procedures performed. Osteosynthesis to the orbit and midface played an important role, but also craniotomy and cranial trepanation had to be performed to six patients. A recent study found equine-related accidents to be the most important contributor to sports-related traumatic brain injuries in the USA $(45.2 \%) .{ }^{24}$ The protective effect of riding helmet was shown multiple times before. ${ }^{911} 12$ 25-27 Bilaniuk et al found a significant lower ISS and incidence of intracranial injury in patients wearing a helmet. ${ }^{12}$ A latest review by Zuckerman and colleges showed an absolute risk reduction of $40 \%-50 \%$ for head injuries. ${ }^{28}$ Despite the evidence that helmets are of strong protective use, we still see a big number of severe head injuries. Like Zuckerman et al we thus recommend a mandatory helmet use, not only while riding a horse but for all activities around it. 
Reviewing the literature on major equestrian injuries studies also hints at the serious potential of trunk injuries. ${ }^{1729}$ We confirmed this with the present study. The protective use of riding vests could not be proven so far ${ }^{30}$ and remains an important issue of future prevention research.

Almost one-fifth of the patients suffered spinal injuries, which is confirmed by the literature. ${ }^{12}{ }^{22}$ Those patients had higher odds for being hospitalised and treated on an ICU or IMC, though effects were not significant. Three patients had lesions of the spinal chord or plexus, but the present study did not evaluate the long-term outcome after an accident. Papachristos et $a l^{17}$ reported significantly more ongoing pain and a prolonged recovery time of patients with spine injuries resulting from equestrian incidents.

Most of the open reduction internal fixations (ORIFs) or closed reduction internal fixations (CRIFs) were performed at the limbs. Thus patients with injuries to the upper or lower limbs had the highest odds for undergoing surgery. Since fractures of the long bones are commonly addressed by osteosynthesis, this is sensible from a clinical point of view.

\section{LIMITATIONS}

Due to retrospective design only yet existing information could be evaluated and incomplete documentation remains a reason for loss of data. The amount of observations for males was low in some categories leading to little reliable statements.

Relying on observational data, the analysis might suffer from selection bias. For example, it is possible that severe injuries are over-represented in one group, for example, adult male, as they are less likely to go to the hospital with mild injuries compared with other groups. In addition, some groups could have preferences for hospitals in the surroundings. If these preferences are non-randomly distributed, results are biased. However, even advanced sample selection methods are of little use here since we do not have data on persons that get injured but decide to not see a doctor.

\section{CONCLUSION}

Equestrian sports bear the risk for serious injuries. More females and young individuals participate in equestrian sports and therefore are injured more frequently. However, we defined men and individuals of higher age as groups of a higher risk for serious injuries. We thus conclude a necessity of reassessment in prevention questions and see a chance for the improvement of injury prevention.

Caution is required when treating patients of younger age after an equine-related accident since final risk evaluation remains unclear. We confirm that horseback riding as well as handling the horse bears a comparable risk for serious injuries.

Head injuries remain a frequent and serious consequence of equestrian sport. The protective use of helmets was confirmed before, and we again emphasise their use in all situations with the horse.

Contributors All authors have approved the revised manuscript and have contributed to this work and are therefore listed in the authors list.

Funding The authors have not declared a specific grant for this research from any funding agency in the public, commercial or not-for-profit sectors.

Competing interests None declared.

Patient consent Not required.

Ethics approval The design and conduct of this study was approved by the Ethics Committeeof the University Medical Centre Goettingen.

Provenance and peer review Not commissioned; externally peer reviewed.

Open access This is an open access article distributed in accordance with the Creative Commons Attribution Non Commercial (CC BY-NC 4.0) license, which permits others to distribute, remix, adapt, build upon this work non-commercially, and license their derivative works on different terms, provided the original work is properly cited, appropriate credit is given, any changes made indicated, and the use is non-commercial. See: http://creativecommons.org/licenses/by-nc/4.0/

\section{REFERENCES}

1. Weber CD, Nguyen AR, Lefering $R$, et al. Blunt injuries related to equestrian sports: results from an international prospective trauma database analysis. Int Orthop 2017;41:2105-12.

2. Abu-Kishk I, Klin B, Gilady-Doron N, et al. Hospitalization due to horse-related injuries: has anything changed? A 25 year survey. Isr Med Assoc J 2013;15:169-72.

3. Laurent R, Uhring J, Bentahar M, et al. [Epidemiology of equestrian injuries in children]. Arch Pediatr 2012;19:1053-7.

4. Loder RT. The demographics of equestrian-related injuries in the United States: injury patterns, orthopedic specific injuries, and avenues for injury prevention. J Trauma 2008;65:447-60.

5. Havlik HS. Equestrian sport-related injuries: a review of current literature. Curr Sports Med Rep 2010;9:299-302.

6. Altgärde J, Redéen S, Hilding N, et al. Horse-related trauma in children and adults during a two year period. Scand J Trauma Resusc Emerg Med 2014;22:40.

7. Craven JA. Paediatric and adolescent horse-related injuries: does the mechanism of injury justify a trauma response? Emerg Med Australas 2008;20:357-62.

8. Ghosh A, Di Scala C, Drew C, et al. Horse-related injuries in pediatric patients. J Pediatr Surg 2000;35:1766-70.

9. Mayberry JC, Pearson TE, Wiger KJ, et al. Equestrian injury prevention efforts need more attention to novice riders. J Trauma 2007;62:735-9

10. Sorli JM. Equestrian injuries: a five year review of hospital admissions in British Columbia, Canada. Inj Prev 2000;6:59-61.

11. Abu-Zidan FM, Rao S. Factors affecting the severity of horse-related injuries. Injury 2003;34:897-900.

12. Bilaniuk JW, Adams JM, DiFazio LT, et al. Equestrian trauma: injury patterns vary among age groups. Am Surg 2014;80:396-402.

13. Johns E, Farrant G, Civil I. Animal-related injury in an urban New Zealand population. Injury 2004;35:1234-8.

14. Cuenca AG, Wiggins $A$, Chen MK, et al. Equestrian injuries in children. J Pediatr Surg 2009;44:148-50.

15. Thomas KE, Annest JL, Gilchrist J, et al. Non-fatal horse related injuries treated in emergency departments in the United States, 2001-2003. Br J Sports Med 2006;40:619-26.

16. Carmichael SP, Davenport DL, Kearney PA, et al. On and off the horse: mechanisms and patterns of injury in mounted and unmounted equestrians. Injury 2014;45:1479-83.

17. Papachristos A, Edwards E, Dowrick A, et al. A description of the severity of equestrian-related injuries (ERIs) using clinical parameters and patient-reported outcomes. Injury 2014;45:1484-7.

18. Eilers $\mathrm{PHC}$, Marx BD. Flexible smoothing with $B$-splines and penalties. Statistical Science 1996;11:89-121.

19. R: A language and environment for statistical computing. $R$ foundation for statistical computing program. Vienna, Austria: R Core Team, 2016.

20. Schicho A, Einwag D, Gebhard F. Schwerverletzte durch unfälle im reitsport. Dtsch Z Sportmed 2014a;09:258-61.

21. Weber EU, Blais A-R, Betz NE. A domain-specific risk-attitude scale: measuring risk perceptions and risk behaviors. J Behav Decis Mak 2002;15:263-90. 
22. Schröter C, Schulte-Sutum A, Zeckey C, et al. [Accidents in equestrian sports : Analysis of injury mechanisms and patterns]. Unfallchirurg 2017;120:129-38.

23. Lang J, Sathivelu M, Tetsworth K, et al. The epidemiology of horserelated injuries for different horse exposures, activities, and age groups in Queensland, Australia. J Trauma Acute Care Surg 2014;76:205-12.

24. Winkler EA, Yue JK, Burke JF, et al. Adult sports-related traumatic brain injury in United States trauma centers. Neurosurg Focus 2016;40:E4.

25. Hasler RM, Gyssler L, Benneker L, et al. Protective and risk factors in amateur equestrians and description of injury patterns: $A$ retrospective data analysis and a case - control survey. J Trauma Manag Outcomes 2011;5:4.

26. Hawson LA, McLean AN, McGreevy PD. The roles of equine ethology and applied learning theory in horse-related human injuries.
Journal of Veterinary Behavior: Clinical Applications and Research 2010;5:324-38.

27. McIntosh AS, Andersen TE, Bahr R, et al. Sports helmets now and in the future. Br J Sports Med 2011;45:1258-65.

28. Zuckerman SL, Morgan CD, Burks S, et al. Functional and structural traumatic brain injury in equestrian sports: a review of the literature. World Neurosurg 2015;83:1098-113.

29. Ball CG, Ball JE, Kirkpatrick AW, et al. Equestrian injuries: incidence, injury patterns, and risk factors for 10 years of major traumatic injuries. Am J Surg 2007;193:636-40.

30. Hessler C, Eckert V, Meiners J, et al. [Causes, injuries, therapy and possibilities of prevention of equine-related accidents. Results of a 2-center-study]. Unfallchirurg 2014;117:123-7. 